\title{
Aspectos obstétricos, sócio-demográficos e psicossociais de puérperas adolescentes assistidas pelo sistema de saúde do município de Muriaé - Zona da Mata Mineira, Brasil.
}

\author{
Aspects obstetrics, social-demographic and psychosocial of puerpera teenagers \\ assisted by the Health System, in the municipality of Muriaé (Zona da Mata \\ Mineira) in the state of Minas Gerais, Brazil.
}

Resumo de tese

Gravidez na adolescência Pré-natal

Condições sócio-demográficos Condições psicossociai Condições obstétricas

Keywords:

Teenage pregnancy

Prenatal care

Social-demographic conditions

Psychosocial conditions

Obstetrics conditions
Dissertação apresentada ao Programa de Mestrado Profissional em Saúde da Família, da Universidade Estácio de Sá - Rio de Janeiro, para obtenção do título de Mestre, em 26 de abril de 2010.

OBJETIVO: estabelecer o perfil da gravidez na adolescência em população assistida pelo Sistema de Saúde no município de Muriaé - Zona da Mata Mineira. METODOLOGIA: através de estudo observacional, de natureza transversal, de base populacional, foram analisados dados de 120 entrevistas de puérperas adolescentes (12 a 19 anos), correspondente a todos os partos de adolescentes ocorridos no município, de Julho a Dezembro de 2009. 0 estudo foi aprovado pelo Comitê de Ética e Pesquisa da Univ. Estácio de Sá (Prot. No 36/09). Obteve-se a prevalência dos dados: sócio-demográficos, obstétricos e ginecológicos, de cunho psicossociais, que motivaram a adolescente a engravidar, psicossociais relacionados à percepção da mãe adolescente por conta da gravidez, emocionais e do Pré-Natal. Os dados foram ainda submetidos à análise bivariada, relacionados à idade materna, situação conjugal e agravos de natureza obstétrica. RESULTADOS: a prevalência de gravidez na adolescência em Muriaé foi de 16,2\%, estando 25,0\% no grupo precoce (12 a 16 anos). Neste grupo, a maioria era residente na zona urbana, de cor não branca, com união consensual, não desejou a gravidez, mas sentiu-se satisfeita com a gestação; os pais dos bebês não desejaram a gravidez, porém, assim como a família, reagiram positivamente com a notícia; sentiu-se apoiada pelo pai do bebê e por sua família; dentre as que estudavam $94,0 \%$ não abandonaram os estudos ao engravidar; relataram menarca $<12$ anos, início da atividade sexual $<15$ anos, idade $1^{a}$ gestação $>14$ anos; não usavam método anticoncepcional, eram primíparas, fizeram pré-natal com Médico e na Atenção Básica. No grupo tardio (16 a 19 anos), a maioria apresentou cor da pele não branca, não estavam estudando ao engravidar, não desejaram a gravidez, não tiveram apoio do pai do bebê, ficaram insatisfeitas com a gestação, não usavam método anticoncepcional, relataram antecedentes de aborto e parto não vaginal. As adolescentes com união consensual apresentaram a maioria, cor não branca, $1^{a}$ gestação $\leq 14$ anos, não estavam estudando ao engravidar, não pretendiam trabalhar, não desejaram a gravidez e teve reação familiar negativa. As adolescentes sem união consensual disseram-se insatisfeitas com a gestação e não foram apoiadas pelo pai do bebê. CONCLUSÕES: a gravidez na adolescência foi vivida de forma difícil e conflituosa por muitas adolescentes e seus familiares. Trouxe limitações sociais, educacionais e profissionais. Entretanto, as adolescentes entrevistadas, de modo geral, puderam contar com o apoio do pai do bebê ou de familiares e tiveram amplo acesso aos serviços de saúde. 